\title{
Design of an environmental assessment model on the effect of vehicle emission in greater Tehran on air pollution with economic sensitivity
}

\author{
${ }^{1 *}$ M. Abbaspour and ${ }^{2}$ A. Soltaninejad \\ ${ }^{1}$ Department of Mechanical Engineering, Sharif University of Technology, Tehran, Iran \\ ${ }^{2}$ Department of Environmental Engineering, Graduate School of the Environment and Energy, Islamic Azad University, \\ Science and Research Campus Tehran, Iran
}

\begin{abstract}
Air pollution is the presence of pollutants in the atmosphere from anthropogenic or natural substances in quantities likely to harm human, plant or animal life; to damage human-made materials and structures; to bring about changes in weather or climate; or to interfere with enjoyment of life or property. With regard to the quality of air in most of the megacities of the world, vehicular air pollution plays an important role in deteriorating air quality. Air pollution in Tehran (Capital of the Islamic Republic of Iran) occurs in highly urbanized areas due to mobile anthropogenic sources which in-turn is hastened by unfavorable tohion sector is responsible for much of urban air pollution and can result in high ambient concentrations that harm people, structures, and environment. This paper examines and estimates the tonnage, concentrations and impacts of air pollutants along with control measures aimed at reducing the effect of pollutants released by transportation navigation, in Tehran.
\end{abstract}

Key words: Tehran air pollution, economic evaluation of pollution, vehicle emission *Corresponding Author, E-mail: m-abbaspour@jamejam.net

\section{Introduction}

Like all other megacities of the world, Tehran; The capital of Iran is very much bound to transportation navigation for its economic activities, hence transportation system plays an important role in all aspects of economic and social activities, moreover, transportation has a number of positive and negative impacts on quality of life and environment. It creates easy accessibility to workplaces, and makes mobility of people much comfortable (positive effects). Environmental effects of transportation in highly urbanized areas include air pollution, health effects and many other environmental deterioration (negative effects). In light of the above issues of environment, this paper (i) discuss the quantification of tonnage pollutant in Tehran, (ii) concentration methodologies for identification of death rate due to air pollutants. (iii) cost-benefit evaluation of emission control (economic sensitivity) and (iv) discusses programs aimed standard at reducing the amounts of pollutants released by transportation navigation in Tehran (Iran).

\section{Tehran's environmental issues}

Besides all other environmental problems, air pollution due to transportation is one of the most important problem in Tehran, and this has affected the planning and developments of many major projects including transportation navigation projects. Transportation is a major contributor of principal green house gas (carbon dioxide) and the atmosphere of Tehran is polluted with carbon monoxide, hydrocarbons, oxides of nitrogen, lead, sulphur oxides and particulate matter released mostly by mobile sources. The air pollution legislation in the Islamic Republic of Iran included the air pollution prevention Act of 1994, according to the article 4 of 1994 . Act, the use of highly smoked vehicles are prohibited and automobile air pollution standards based on European standard, ECE 1504 or equivalent 83/351/EEC have been created and automobile manufacturers and importers have been asked to specify recommended control strategies. A council of environmental quality have been created giving the power to set national air quality 
standards and to require highly air polluted provinces such as: Tehran, Isfahan, Tabriz and Mashhad, to develop implementation plans to meet mandatory legislative. The 1999 emission regulation polluted provinces such as: Tehran, Isfahan, Tabriz and Mashhad, to develop implementation plans to meet mandatory legislative. The 1999 emission regulation standard with major impacts on transportation and project development in studied area is not meeting the National Ambient Air Quality standards.

\section{Pollutants released from transportation navigation activities}

The vehicle fleet and motorization, with large number of old and poorly maintained vehicles as well as growing domestic vehicles are responsible for much of the recognized pollutants discharged to the atmosphere in metropolitan areas of Tehran. The transportation related pollutants are carbon monoxide (CO), reactive and non-reactive hydrocarbons, nitrogen oxides, $\left(\mathrm{NO}_{\mathrm{x}}\right)$ sulfur oxides $\left(\mathrm{SO}_{\mathrm{x}}\right)$, and lead $(\mathrm{pb})$.

\section{Categories of emission source}

There are two categories of emission source in Tehran.

- Mobile sources, including:

- Passenger cars and light duty trucks

- Heavy duty trucks and buses, and motor cycles.

- Aircrafts

- Land use area complexes, including shopping centers, airports, terminals and sport stadiums, where large number of transport activities occur

- Stationary sources, including:

- Heating and discharge of volatileorganic vapors.

- Fossil-fuel-fired steam generators.

- Industrial-commercial-institutional generating units

- Incinerators

- Hot asphalt facilities

- Cement plant

- Petroleum refinery

Mobile sources account for 70 percent of pollutants released into the atmosphere of Tehran.

\section{Variables affecting vehicular emissions}

Unfavorable topographical and meteorological conditions, starting in cold, engine idling periods, accelerations, speeds and driving patterns affect dispersion and transport of toxic chemical pollutants released from vehicles. The following are the most important variables affecting vehicular emissions: Vehicle speed is a factor that affects vehicular emissions, HC, CO, SO2, TSM, emissions are higher at slower speeds and with increase in speed especially above $70 \mathrm{~km} / \mathrm{h}$, the amount of pollutants will be dramatically decreased. Atmospheric temperature is another important variable in the production of pollutants, with increase in temperature the tonnage of pollutant will be decreased, and warmed up vehicles have lower emission than the cold ones. The higher the temperature of the environment, the lower will be the emission of pollutants.

$\mathrm{L}_{\mathrm{v}}$ (Vehicle Kilometers Traveled) is a factor affecting vehicular emissions, $L_{v}$ increase causes the pollutant to increase in higher rates.Wind speed is a variable that affects the concentration of emission in the atmosphere, higher wind-speed, decreases the concentration of HC and CO. (v) Relative humidity, inversion height and inversion mixing ratio $(\mathrm{g} / \mathrm{kg})$ are among other environmental factors that may affect the tonnage and concentration of pollutants in Tehran. (vi) Vehicle class, model year, fuel delivery system, inspection and maintenance and emission control system are vehicular parameters that must be taken into account while considering vehicular discharge of pollutants to the atmosphere.

\section{Pollutant emission from transportation}

90 percent of total CO emission in Tehran is produced by light and heavy duty vehicles, 9 percent by motor cycles and 1 percent by heavy duty trucks. 71 percent of $\mathrm{SO}_{2}$ is produced by heavy duty trucks. 64.3 percent of hydrocarbons are produced by light and heavy duty vehicles, motor cycles are emitting 27.6 percent of hydrocarbons in Tehran.

$\mathrm{NO}_{\mathrm{x}}$ is emitted with following percentage. Light duty vehicles and light duty trucks 48 percent, mini bus 5 percent, truck 44 percent, and buses 3 percent.

PM-10 emission rate is as follow: Light duty vehicles and light duty truck $52 \%$, mini 
bus $13 \%$, truck 29\%, bus 3\%, MC $6 \%$ (miscellaneous).

Total annual emissions from mobile sources have been calculated (Soltanieh, et al., 1997,) as follow:

- 9.4 million tons of $\mathrm{CO}_{2}$

- 20,500 tons of PM-10

- 17,458 tons of $\mathrm{SO}_{2}$

- $1,284,443$ tons of $\mathrm{CO}$

- 104,042 tons of $\mathrm{NO}_{\mathrm{x}}$

- 115,643 tons of NMVOC (non-methane hydrocarbons (AQCC, 1997)

Concentration of pollutants released from motor vehicles in Tehran is dramatically very high, (Soltanieh, et al., 1997), following results have been obtained during an analysis of the measurement of $\mathrm{SO}_{2}, \mathrm{CO}, \mathrm{NO}_{2}$, and PM-10.

$\mathrm{SO}_{2}$ : The maximum 24 hour average value was found at central areas of Tehran, $393 \mu \mathrm{g} / \mathrm{m}^{3}$.

NO2: The maximum 24 hour average value was found at central areas of Tehran, $246 \mu \mathrm{g} / \mathrm{m}^{3}$. CO:The maximum 8- hour average value was found at central areas (Fatemi district) of Tehran, $31 \mathrm{mg} / \mathrm{m}^{3}$. Pb: Tetra ethyl lead is used as an anti-knock compound in motor fuel and even the leaded regular (unleaded grades) is having the highest content of lead, (0.22 g/liter) Lead additive have been almost eliminated from motor fuel in most of the countries of the world and its substitution with MTBE (Methyl Tert-Butyl Ether) is under consideration in Islamic Republic of Iran. All the above mentioned values do not meet the WHO and National Air Quality recommendations.

\section{Emission standards:}

\section{New and imported cars}

Emission standards for new and imported cars in the Islamic Republic of Iran were first established by the 1993 Clean Air Act, which was amended in 1999 (DOE,1999). These standards, limited $\mathrm{CO}, \mathrm{HC}$, and $\mathrm{NO}_{\mathrm{x}}$ emissions from vehicle exhaust gases. Table 1 shows emission standard for petrol fueled vehicles. established in 1994 and its executive articles have been prepared by High Council for the Environment in 1998: According to these standards, in-use gasoline fueled vehicles must comply with the content of Table 2 . The above standards are effective from year 1999, first in Tehran and after providing facilities they will become effective in other cities of the Islamic
Table 1: Emission standards for petrol-fueled vehicles(*) in Iran based on ECE 1504 type approval (new and imported), (DOE,1999)

\begin{tabular}{|l|cc|}
\hline Reference Weight (kg) $^{* *}$ & $\begin{array}{c}\mathrm{CO} \\
\text { (g/test) }\end{array}$ & $\begin{array}{c}\mathrm{HC}+\mathrm{NO}_{\mathrm{X}} \\
\text { (g/test) }\end{array}$ \\
\hline $\mathrm{RW} \leqslant 750$ & 58 & 19 \\
$750<\mathrm{RW} \leqslant 850$ & 58 & 19 \\
$850<\mathrm{RW} \leqslant 1020$ & 58 & 19 \\
$1020<\mathrm{RW} \leqslant 1250$ & 67 & 20.5 \\
$1250<\mathrm{RW} \leqslant 1470$ & 76 & 22 \\
$1470<\mathrm{RW} \leqslant 1700$ & 84 & 23.5 \\
$1700<\mathrm{RW} \leqslant 1930$ & 93 & 25 \\
$1930<\mathrm{RW} \leqslant 2150$ & 101 & 26.5 \\
$2150<\mathrm{RW}$ & 110 & 28 \\
\hline
\end{tabular}

*fueled vehicles are those designed to carry up to twelve passengers as well as lightduty commercial vehicles, designed to carry fright.

**Reference Weight is the weight of vehicle without load, passenger and driver plus 100 kilograms and its full tank

Table 2: Exhaust emission standards for in-use gasoline fueled vehicles

\begin{tabular}{|c|c|c|c|c|}
\hline $\begin{array}{c}\text { Pollutant } \\
\text { type }\end{array}$ & $\begin{array}{c}\text { The } \\
\text { effective } \\
\text { year } \\
(1998)\end{array}$ & $\begin{array}{c}1^{\text {st. }} \\
\text { year }\end{array}$ & $\begin{array}{c}2^{\text {nd. }} \\
\text { year }\end{array}$ & $\begin{array}{c}3^{\text {rd. }} \\
\text { year }\end{array}$ \\
\hline CO & $6.5 \%$ & $6 \%$ & $5 \%$ & $4 \%$ \\
& volume & volume & volume & volume \\
HC & 700 & 600 & 500 & 400 \\
& ppm. & ppm. & ppm. & ppm. \\
\hline
\end{tabular}

Republic of Iran. From the above mentioned regulations. It is evident that the current trend is suffering from the lack of proper regulations, and therefore the procedure should carried in a fast pace.

\section{Atmospheric cleansing and emissions in Tehran}

Basic atmospheric clean up processes are responsible for removal of pollutants in a polluted area, movement and diffusion of toxic gases released from vehicles in Tehran is very weak due to unfavorable meteorological and topographical conditions and chemical conversion of pollutants in the air of Tehran involves no favorable interactions associated with atmospheric cleansing. Other natural processes that remove certain pollutants from the air are also jeopardized due to poor chemical reactions. 
As noted earlier, meteorological variables such as wind speed, inversion mixing ratio, and wind speed and its direction determine atmospheric dispersion of pollutants, since, the wind speed and its direction over the surface area of Tehran is not in the order of real and full dispersion pattern, due to non functional turbulent, the movement and dispersion of pollutant is much less in Tehran. Inversion is another factor which interrupts the dispersion of pollutants and causes their accumulation in the atmosphere.Once exhaust gases reach the atmosphere, they are subjected to various chemical reactions. The interactions between pollutants is powered by sunlight, hence thermal induction is available and followed by chain chemical reactions which yield a strong oxidant, called photochemical smog.

There are several natural mechanisms that the clean atmosphere from certain pollutants these mechanisms, in brief include:

- Aerosol formation.

- Water cloud formation

- Precipitation

Each of the above mechanisms remove pollutants from the atmosphere within the specified length of time, depending on water solubility and chemical reactivity of the pollutants.

Due to unfavorable climatic conditions created mostly by vehicular emission, the natural clean up mechanisms are no longer functioning, thereby detrioration of air quality has become a major environmental issue in Tehran.

\section{Methodology}

A data-based modeling framework (Wadhwa, 1993) was exercised and long-term data (from 1991 to 1999) on all the input variables and actual ambient concentration of pollutants for model validations were made available from different and related institutions in Tehran, on a monthly basis average i-e DOE , Iranian Meteorological Organization and Ministry of Industry. Estimation of emission quantity, ambient concentration and impacts on health were determined with the aid of the following functions:

Quantity $=\mathrm{f}_{1}$ (Vehicle Kilometers Traveled (VKT),atmospheric temperature (weather), vehicle-speed, relative -humidity)or Quantity: $f_{1}(\mathrm{Lv}, \mathrm{Ta}, \mathrm{Vs}, \mathrm{RH})$.

Concentration $=\quad f_{2} \quad$ (quantity, VKT, temperature, wind-speed, vehicle-speed, relative.humidity, inversion-mixing ratio).or Concentration:

$f_{2}$ (Qp,Lv,Ta,Ws,Hi,Mr) Impacts: $f_{3}(\mathrm{Cp}$, $\mathrm{CH}, \mathrm{Np}$ ).

On the basis of the above frameworks, multiple regression models were applied and detailed relationships between quantity, concentration and impacts, and all other inputvariables were determined.

Tons of pollutants by type ( $\mathrm{HC}, \mathrm{CO}, \mathrm{NO}_{2}$, $\mathrm{SO}_{2}, \quad \mathrm{PM}-10$ ) emitted in Tehran, and concentration of pollutants and their effects on human health (deaths) were determined.

\section{Modeling results \\ Estimation of pollutant quantity}

In order to quantify pollutant emissions from mobile sources, an emission inventory was developed through multiple regression model and the results show (Table 3), that the use of a multiple regression model with defined independent variables (V. Speed, $\mathrm{VKT}$, temp, R.Humidity) can determine 90 percent of changes of dependent variable $\mathrm{Q}$ (Quantity of CO pollutant in Tehran).

For estimation of the amount of other pollutants (HC, $\mathrm{PM}-10, \mathrm{NO}_{2}$,etc) the above mechanism was applied too. As it is shown in the Table 3 vehicle-speed, and temperature show negative signs, it means that with one unit increase in each of the above independent variables, (the values shown in Table 3).

The tonnage of $\mathrm{CO}$ is reduced dramatically. VKT increases the amount of carbon monoxide. The $\mathrm{CO}$ and $\mathrm{HC}$ tonnage is calculated as follows:

$$
\begin{aligned}
& \text { CO/ton }=1054845.7-14160.286 \\
& (\mathrm{Vs})+2244.559(\mathrm{Lv})-7512.738(\mathrm{Ta}) \\
& -1741.818(1)(\mathrm{RH})
\end{aligned}
$$

HC/ton $=455540.64$

5753.495(Vs)+1483.277(Lv)-2231.963(Ta) $-479.940(\mathrm{RH})$

Figures 1 and 2 show the relationship between vehicle-speed and $\mathrm{CO}$ and $\mathrm{HC}$ emissions. 
Estimation of pollutant concentration

Ambient concentrations of pollutants by motor vehicles are the result of a number of meteorological and topographical factors.

For estimation of concentration of pollutants, a multiple regression model was applied and all input variables such as Vs, Lv, Ta, Ws, RH, Hi, Mi (g/kg) and total quantity of pollutants were taken into account as independent variables. The dependent variable is total concentration of pollutants in $\mu \mathrm{g} / \mathrm{m}^{3}$.

The use of multiple regression model showed that wind-speed is dramatically decreases the concentration of pollutants. (Table 4) and vehicle-speed and inversionmixing ratio increases the concentration of pollutants.

The other independent variables have not been considered significant since they are at 0.05 level correlation.

\section{Health effects}

Most of the exhaust pipe gas emissions emitted by transportation navigation in Tehran, have a large number of adverse health effects including deaths in human population level. In order to evaluate the effects of motor vehicle pollutants on respiratory and cardiovascular system including cancer deaths, a multiple regression model with all the input variables were applied and the results are shown in Table 5. The following are the variables used in multiple regression model Impact:

Total number of Respiratory, Cardiovascular systems, and Cancer deaths, (RCC) as dependent variable in Tehran (deaths related to air pollution).

$\mathrm{CH}, \mathrm{C}$, and $\mathrm{Np}$ are used as independent variables:

a)Impact $=$ Total number of RCC deaths in Tehran.

b)0.01 level correlation is considered as significant. According to the modeling results presented in Table 5, it is evident that increase in pollutants concentration and human population results in more human deaths due to vehicular air pollution. As the results show, one unit increase in concentration of pollutants, the air pollution related deaths increases up-to 0.113 unit.

Table 3: Coefficients of dependent variable $\mathrm{Q}^{(\mathrm{a})}$

\begin{tabular}{|c|c|c|c|c|c|}
\hline \multirow{2}{*}{ Model } & \multicolumn{2}{|c|}{ Unstandardized Coefficients } & \multirow{2}{*}{$\begin{array}{c}\text { Standardized } \\
\text { Coefficients } \\
\text { Beta }\end{array}$} & \multirow{2}{*}{$\mathrm{T}$} & \multirow{2}{*}{$\operatorname{Sig}^{(b)}$} \\
\hline & B & S.E & & & \\
\hline (Constant) & 1054845.7 & 547633.10 & & 1.926 & 0.057 \\
\hline Vehicle-Speed & -14160.286 & 1248.472 & -0.883 & -11.024 & 0.000 \\
\hline VKT & 2244.559 & 994.345 & 0.195 & 2.257 & 0.026 \\
\hline Temp & -7512.738 & 1073.267 & -0.538 & -7 & 0.001 \\
\hline Relative-h & -1741.818 & 756.669 & -0.168 & -2.302 & 0.023 \\
\hline
\end{tabular}

a: Q= Quantity of pollutant (CO, in ton).

b: 0.01 level correlation has been taken into account as significant.

Table 4: Coefficients of dependent variable $C^{(a)}$ (concentration)

\begin{tabular}{|c|c|c|c|c|c|}
\hline \multirow{2}{*}{ Model } & \multicolumn{2}{|c|}{ Unstandardized Coefficients } & \multirow{2}{*}{$\begin{array}{c}\text { Standarded } \\
\text { Coefficients } \\
\text { Beta }\end{array}$} & \multirow{2}{*}{$\mathrm{T}$} & \multirow{2}{*}{$\operatorname{Sig}^{(\mathrm{b})}$} \\
\hline & B & S.E & & & \\
\hline (Constant) & 25171.146 & 38779.194 & & 0.649 & 0.518 \\
\hline Vs & 854.183 & 227.979 & 0.648 & 3.747 & 0.000 \\
\hline Lv & -217.331 & 123.450 & -0.229 & -1.760 & 0.081 \\
\hline $\mathrm{Ta}$ & -345.600 & 205.875 & -0.301 & -1.679 & 0.096 \\
\hline Ws & -964.106 & 246.052 & -0.384 & -3.918 & 0.000 \\
\hline RH & -70.108 & 93.357 & -0.082 & -0.751 & 0.454 \\
\hline $\mathrm{Hi}$ & -7.902 & 28.980 & -0.023 & -0.273 & 0.786 \\
\hline $\mathrm{Mr}$ & 3038.420 & 964.781 & -0.321 & 3.149 & 0.002 \\
\hline $\begin{array}{c}\text { Tonnage of } \\
\text { pollutants }\end{array}$ & $-4.124 \times 10^{-3}$ & 0.006 & -0.100 & -0.655 & 0.514 \\
\hline
\end{tabular}

a: C = Dependent variable: Total concentration of pollutants (HC, CO, PM10, $\mathrm{NO}_{2}, \mathrm{SO}_{2}$, etc in $\mu \mathrm{g} / \mathrm{m}^{3}$ )

b: 0.01 level correlation has been taken into account. 


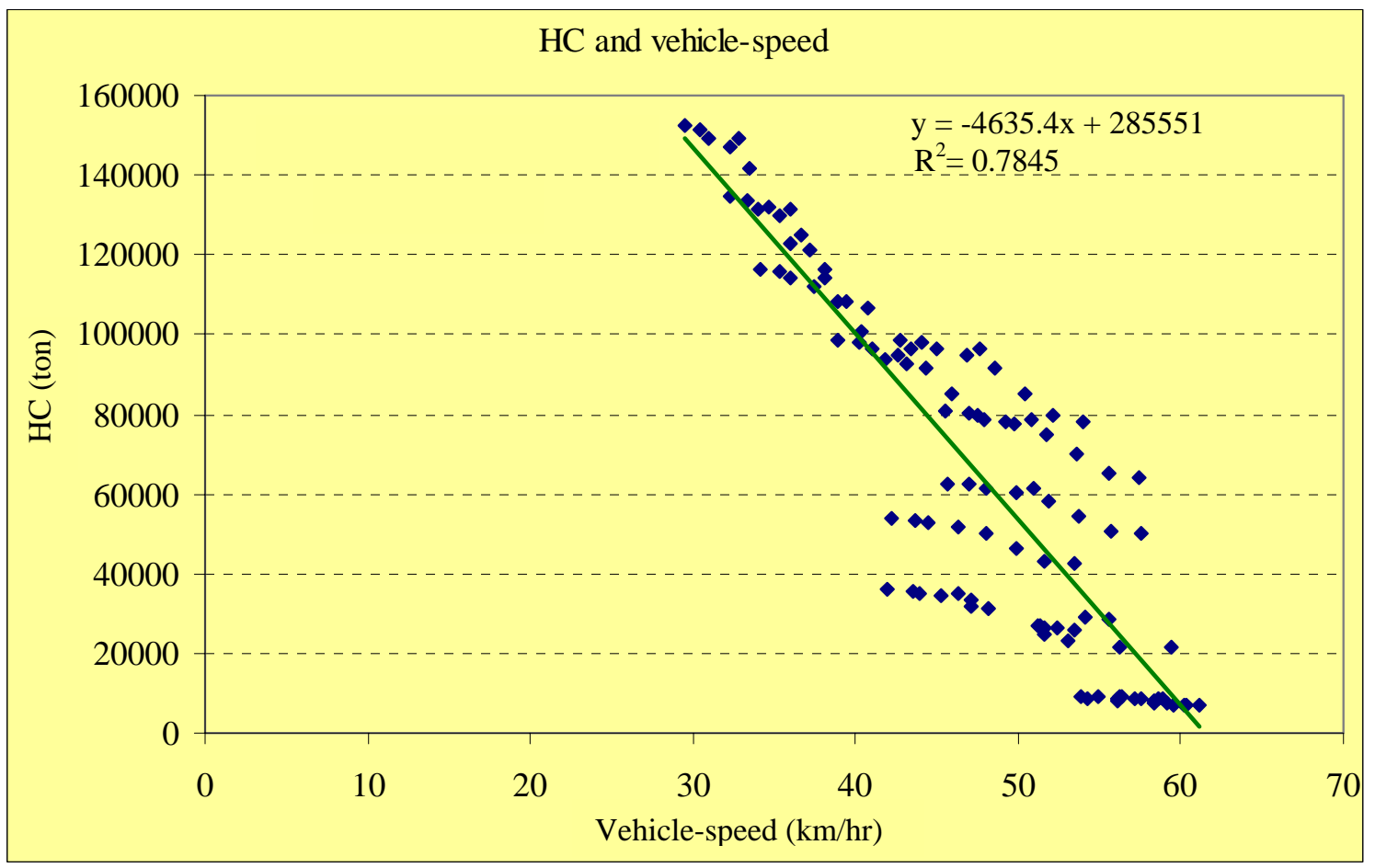

Figure 1: CO emission vs vehicle-speed

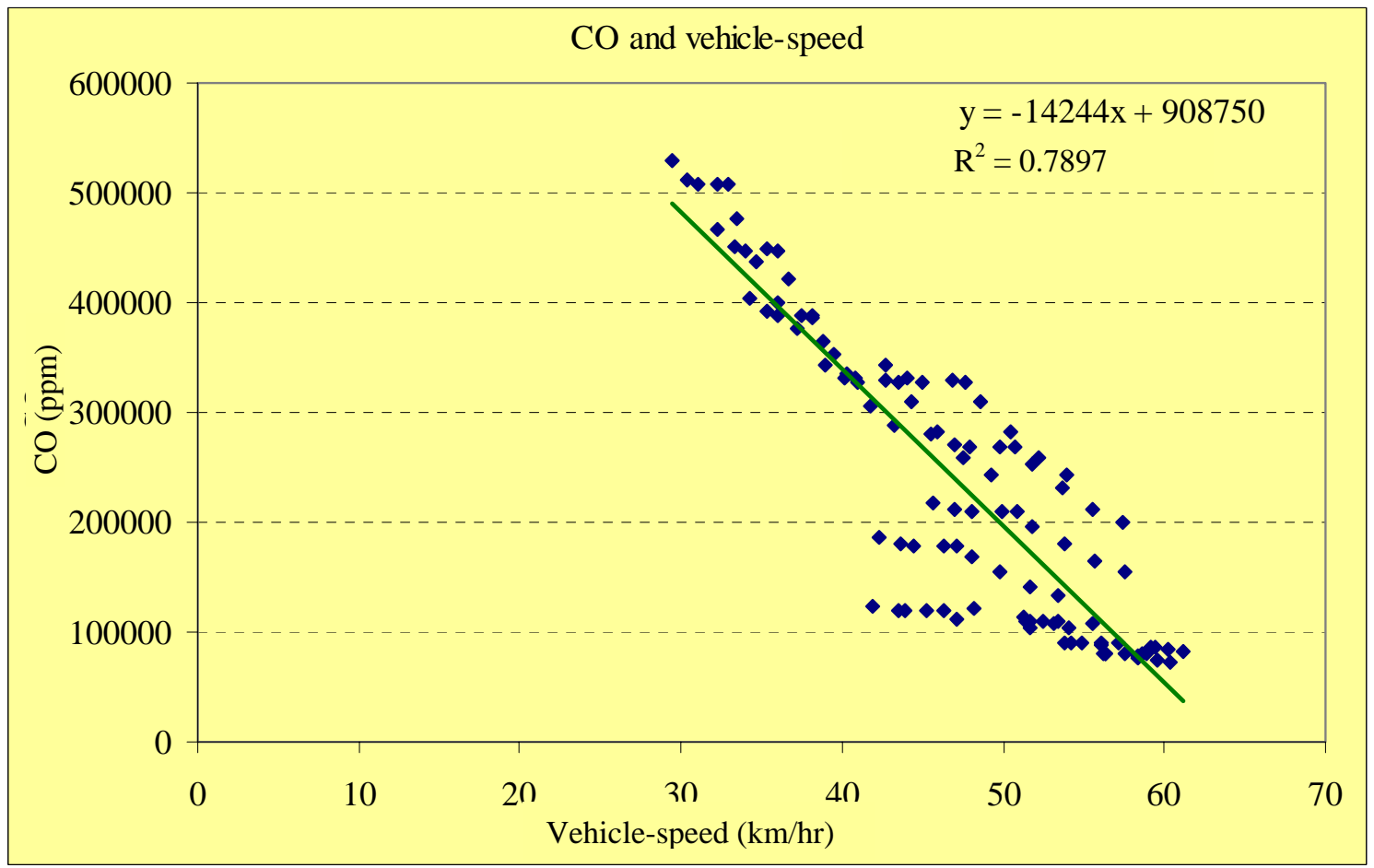

Figure 2: HC emission vs vehicle- speed 


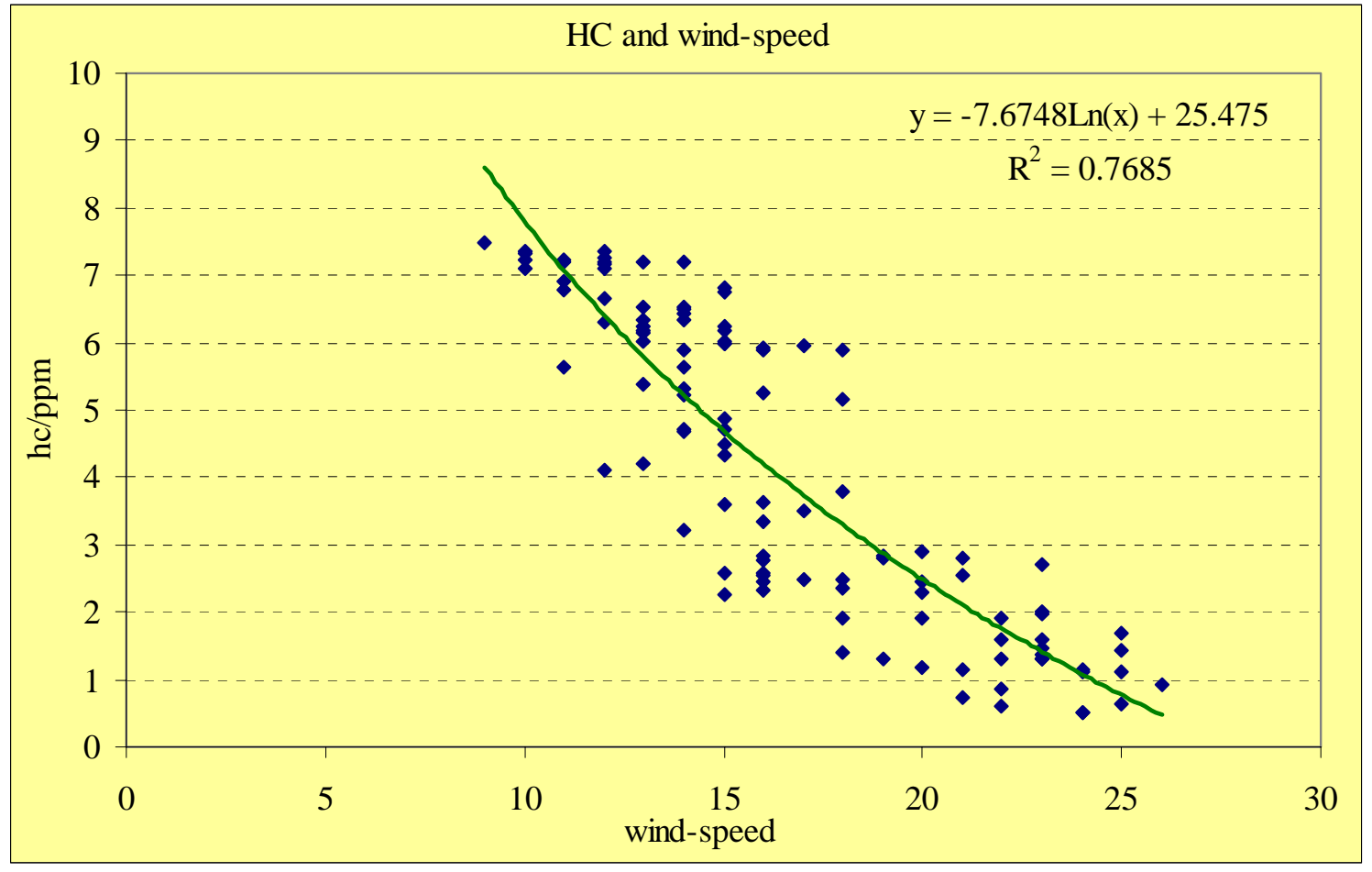

Figure 3: HC concentration vs wind-speed

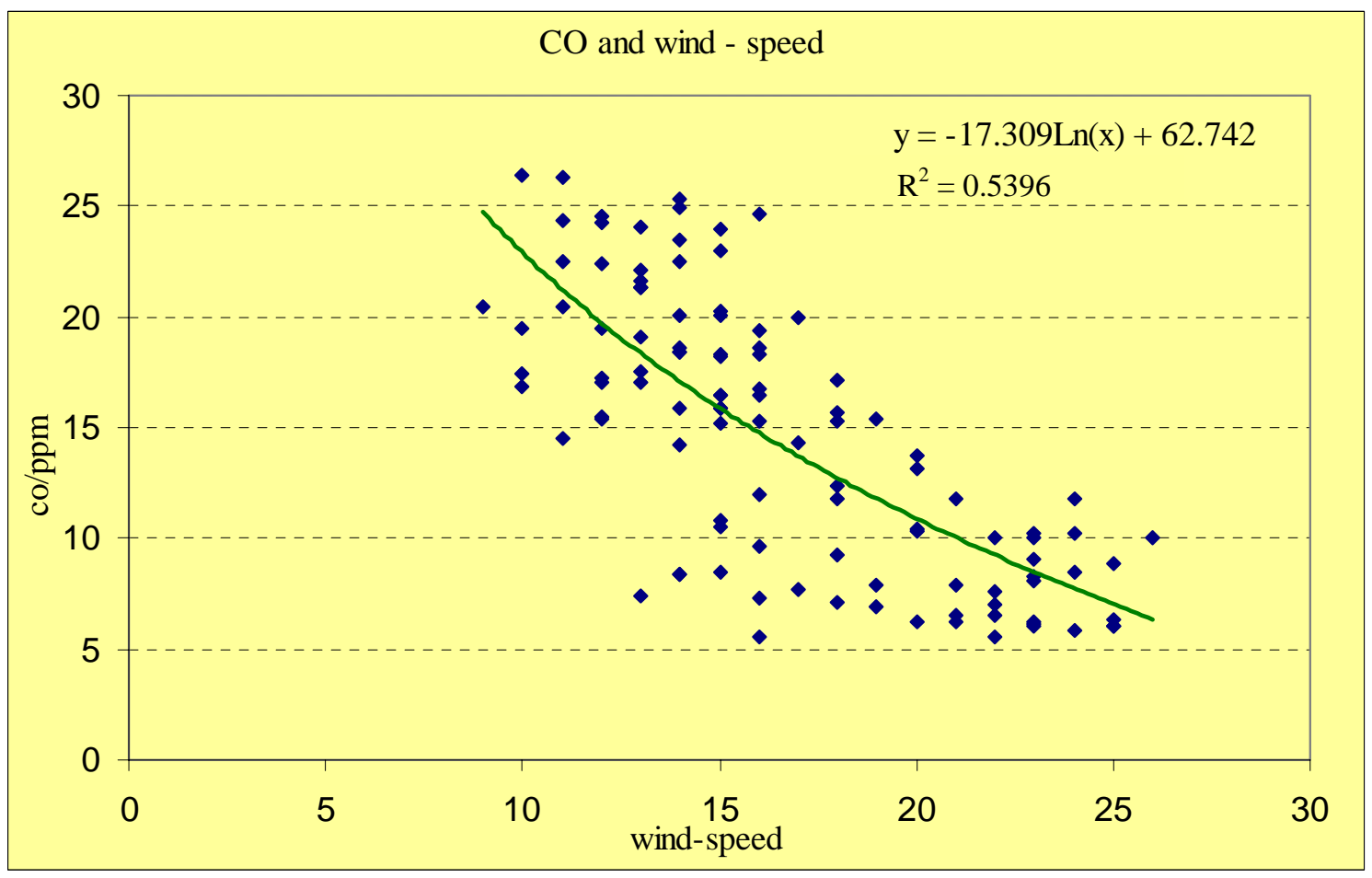

Figure 4: CO concentration vs wind-speed 
Deaths related to the concentration of pollutants $\left(\mu \mathrm{g} / \mathrm{m}^{3}\right)$ are calculated as follows:

$$
\begin{aligned}
& \text { Impact }(\text { Human Loss of Life })=\mathrm{fd} \\
& -23074.051-0.101(\mathrm{CH})+0.113(\mathrm{C}) \\
& +3.408 \times 10^{-3}(\mathrm{~Np})
\end{aligned}
$$

It is obvious that there are many other variables which were ignored in this investigation and this research is focused on the three mentioned variables.

Figure 5 shows the relationship between air pollution deaths and concentration of pollutants $\left(\mu \mathrm{g} / \mathrm{m}^{3}\right)$.
Data of all the above models were analyzed by the Software package called Statistical Package for Social Sciences (SPSS) and the ENTER method from multiple regression model was chosen for the analysis of multiple regression data (Kazemnejad, 2001).

From the analysis of the above models, It is evident that vehicle-speed in the tonnage equation and wind-speed in the concentration equation and concentration itself in air pollution related deaths equation are very sensitive, and in designing and programming for air quality improvement the three mentioned parameters should be taken into

\begin{tabular}{|c|c|c|c|c|c|}
\hline \multirow{2}{*}{ Model } & \multicolumn{2}{|c|}{ Unstandardized Coefficients } & \multirow{2}{*}{$\begin{array}{l}\text { Standarded } \\
\text { Coefficients } \\
\text { Beta }\end{array}$} & \multirow{2}{*}{$\mathrm{T}$} & \multirow{2}{*}{ Sig } \\
\hline & B & S.E & & & \\
\hline Constant & -23074.051 & 4737.677 & & -4.870 & 0.000 \\
\hline Health Cost & -0.101 & 0.056 & -0.119 & -1.806 & 0.074 \\
\hline $\begin{array}{c}\text { Total Concentration } \\
\text { of Pollutants }\end{array}$ & 0.113 & 0.006 & 0.954 & 17.646 & 0.00 \\
\hline Human population & $3.408 \times 10^{-3}$ & 0.001 & 0.336 & 5.050 & 0.000 \\
\hline
\end{tabular}
account.

Table 5: Coefficients of dependent variable impact

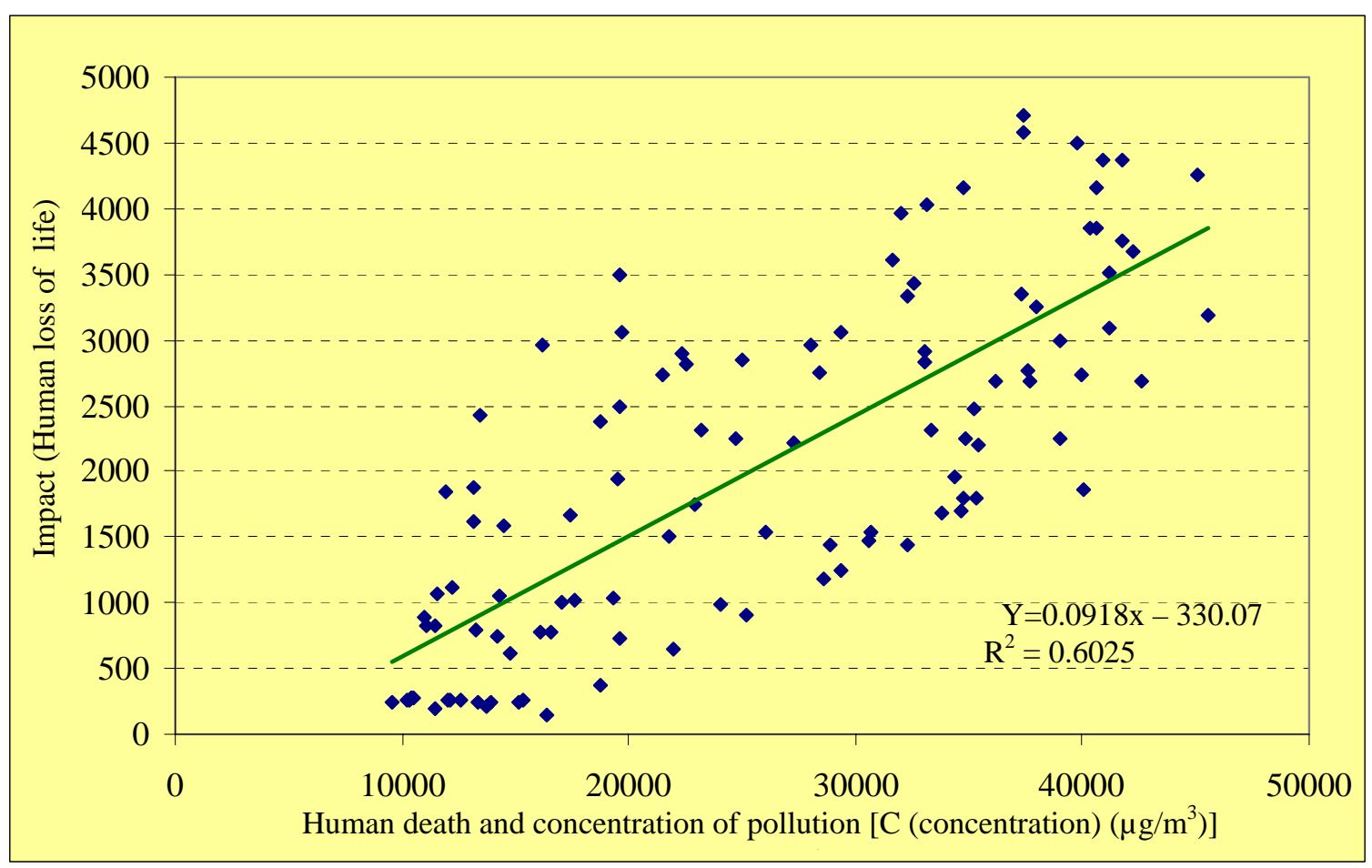

Figure 5: Death vs Concentration 
Economic costs of air pollution (Economic sensitivity)

Economic analysis of air pollution is not a simple task. There are many important variables and their quantification is very difficult, however with increase in air pollution control, the cost of technology for air pollution control also increases and as control increase, the damage resulting from air pollution is reduced.

The total costs of air pollution is the sum of costs to air pollution control and the loss from direct and indirect pollution damages. It is evident that old and poorly maintained vehicles are responsible for much of pollution damage in Tehran.

Therefore, the cost breakdown of this part is presented as follow:

Number of old and poorly maintained vehicles

Old vehicle population during 2000-2001 in Tehran is phenomenal: Reaching 476100 vehicles (SAPCO,1998). It is expected that the old vehicle fleet to grow by about 15 percent annually in Tehran. The above mentioned vehicles consume about 4 million liters of gasoline in addition to their normal daily consumption, therefore, Tehran losses about \$192 millions resulting from gasoline over-use, (pajohi, 1998) in a year and experts say (Soltanieh, 2002) that the cost of annual gasoline evaporative loss from petrol stations is estimated to be $\$ 125$ millions.(\%10 evaporative loss). (world price of 100 liter of petrol is estimated to be $\$ 16$, and annual old vehicles working days $=300$ days $)$.

\section{Costs of Tehran's vehicular air pollution reduction}

In 1999 Department of the Environment of Islamic Republic of Iran announced that the cost of Tehran's Air Quality improvement is estimated to be $\$ 1.9$ billion (DOE,1999) in a 10 year plan.

\section{Costs of human -illness due to air pollution}

According to statistics available (Iran Statistics Center), the total number of people visiting hospitals in Tehran is estimated to be $4,766,892$ in 1998. People visit hospitals due to air pollution is estimated to be \%43 (Bowen, 1970) and the cost of medical treatment is $\$$ 1.875 per person, hence damage resulting from the above visit is calculated as follows:
$\mathrm{CHI}=\mathrm{A} \times \mathrm{B} \times \mathrm{C}$

$3843306=4766892 \times \$ 1.875 \times \% 43$

$C W D=\frac{1558895 \times 12 M O N T H S \times \$ 2.5 \times 70}{100}$

Where:

A = No of people visited hospitals.

$\mathrm{B}=$ Medical Treatment Cost.

$\mathrm{C}=$ Percentage of people who visit hospitals due to air pollution

\section{Cost of life-saving}

Available statistics (Behesht, Zahra Org.1998) indicate that, the total deaths in Tehran is estimated to be 41777 in 1998.It is estimated that air pollution contribute to as many as 1 in 17 deaths(Brown, 1991). Deaths related to air pollution in Tehran is estimated to be 5.7 percent(calculated from the impact equation, Table 5 of this paper) of all deaths in the same year. To save the life, people are willing to pay \$ 32000 (value obtained from 1979 study) per life saved (Schwing, 1979). According to the socio-economic fundamentals of Islam (Davani, 1996) the value of life (willingness to pay) in the Islamic Republic of Iran is estimated to be \$ 16875 based on 2001 study The following calculations determine the cost of life-saving in Tehran.

$$
\begin{aligned}
& C L S=\frac{T D \times P D A P \times W P \times V A P}{100 \times 100} \\
& C L S=\$ 53 \text { million } \\
& C L S=\frac{41777 \times 5.7 \times 70 \times 32000}{100 \times 100}
\end{aligned}
$$

Costs of water usage and detergents for car-wash Total number of vehicles are estimated to be 2000000 in Tehran (Hojat ,Y.,2001) .If the number of motocycles are deduced from vehicle fleet, the remaining will be 1558896 units. If each vehicle is to be washed once in a month due to air pollution and the cost of cleaning is estimated to be \$2.5 for each time of washing, hence, the following calculation determines the total cost of vehicle cleaning due to vehicular air pollution.

$$
C W D=\frac{N V \times 12 \times C C W \times A P T}{100}
$$

$C W D=\$ 33$ million 


\section{Cost of hygiene}

More than 1000000 of Tehran's people are outdoors in each day for various activities, everyone spend \$ 0.475 for extra hygiene once in a week, the total cost of hygiene is estimated to be $\$ 17$ million,in a year.

The following calculation determines the cost of extra-hygiene:

$$
C H=N P \times 52 \times C H P \times A P T
$$

$C H=\frac{1,000,000 \times 52 \times \$ 0.475 \times 70}{100}$

As it is shown in Table 6 the direct costs of air pollution reduction is estimated to be $\$ 1.9$ millions in a 10 year plan and covers the following areas (a) new vehicles (b) old and poorly maintained vehicles (c) public transportation (d) fuel (d)inspection(e)traffic management and (f )training.

Annual indirect costs of air pollution is calculated (Table 6)to be $\$ 424$ millions and taking into account the world bank interest the indirect costs reaches to about $\$ 6$ billions.

According to the above study it is evident that the cost of air pollution abatement is fairly known but it is difficult to adequately determine the loss from air pollution damage particularly when considering health problems and damages to life. It is estimated that every dollar spent on air pollution control saves \$ 20 in health care cost (Cannon,1990). It is obvious that real determination of benefits is a difficult task. In spite of difficulties to determine all benefits it seems bringing to reduce the vehicular air pollution level below mandatory standards.Therefore, to improve the quality of Tehran's air, the sum of $\$ 1.9$ billion is needed and if such an investment takes place, human health benefits will be about $\$ 38$ billion $(1.9 * 20=\$ 38$ billions $)$.

\section{Conclusion}

So far it has been determined that the ambient air quality in Tehran is deteriorating, especially where transportation navigation emissions are left uncontrolled and topographical and meteorological conditions are not suitable for transportation and dispersion of toxic air pollutants. Tehran is one of the most urbanized region in the developing world and suffers from sever air pollution problems. It is located at sufficient high altitudes and surrounded by high wall of mountains that trap pollutant emissions. Human health is seriously affected and no improvements have been taken into account so far. Air pollution control measures must be adopted soon in order to prevent deteriorating ambient air quality created by growing motor vehicle fleet. Growing is-use vehicle fleet, rise in immigration and unfavorable environmental structure are three important environmental issues that hasten air pollution in Tehran. In order to overcome the above said environmental problem, the following suggestions have been chosen to take part as air pollution control measures.

Table 6: Direct and indirect costs of air pollution in Tehran

\begin{tabular}{|l|c|}
\hline $\begin{array}{l}\text { Cost of Tehran's air pollution } \\
\text { reduction (Direct cost) }\end{array}$ & $\$ 1.9$ millions \\
\hline $\begin{array}{l}\text { Cost of gasoline over use and petrol } \\
\text { evaporation (indirect) } \\
\text { Cost of life saving (indirect) }\end{array}$ & $\$ 317$ millions \\
Cost of extra hygiene (indirect) & $\$ 17$ millions \\
Cost of car wash (indirect) & $\$ 33$ millions \\
Cost of human Illness (indirect) & $\$ 4$ millions \\
\hline
\end{tabular}

Old and poorly maintained vehicle fleet Vehicles account for $70 \%$ of emissions released into the air of Tehran and the number of old vehicles is estimated to be 476100 (Hojjat, 2001). The daily average Lv of each vehicle is estimated to be $70 \mathrm{Km}$ and old vehicles have the $\operatorname{Lv} 3$ to 4 times higher than the other vehicles (IDRO, 1998). Over consumption of gasoline for an old vehicle is estimated to be 9.2 liters, in $100 \mathrm{~km} / \mathrm{h}$. Vehicles, especially those which are old and poorly maintained have number of adverse effects on human health. Deaths related to vehicular air pollution in Tehran is estimated to be 4.13 percent and the total death rate due to air pollution is calculated to be 5.8 percent in year 1999. In addition to the above problems the number of passenger trips by old private cars is increasing and the sharp increase in recent years can be attributed to inefficiencies in government public transport. The above situation has created 
difficulties in cooperation, planning, operation, administration, regulation and control of transport system, hence yielding high environmental costs in the form of high air pollution, sub-optimal investments, traffic congestion and finally decreasing the quality of life in Tehran. In order to overcome the above problems, old and poorly maintained vehicles (older than 10 years) can be replaced in an 8 year period, to implement the above program an emergency committee comprising representatives of the transportation sector, municipality,Iran's DOE and vehicle manufacturers must be established and periodical replacement can take place according to the decisions made by the above committee.

\section{Effectiveness of the above program:}

If the old vehicles (older than 10 years), numbering 476100 , are replaced by new ones, the following reduction of toxic gases generated by motor vehicles is obtained, (DOE, 1999).

$\mathrm{CO}=53.5$ percent.

$\mathrm{NO}_{\mathrm{x}}+\mathrm{HC}=47$ percent

In addition to the above reductions, 4 million liters of gasoline will be saved in each day in Tehran (Pajohi, 1998)

\section{Human population reduction:}

The population of Tehran has been grown from about 0.7 million in 1941 to about 6.5 million inhabitants in 1995. The annual rate of urbanization is estimated to be 5.3 (ministry of housing), thus Tehran now is having a population of about $10,000,000$ (in the year 2001). Therefore, Tehran is suffering from overpopulation and as a result of urbanization growth, the vehicle fleet has also grown, infact, air pollution problem is rooted in Tehran overpopulation.

According to plans available, Tehran was designed to shelter 5,000,000 people, but now it is having 10,000,000 population, and as a result, many environmental problems run rampant. To overcome the population dilemma in Tehran, the following methods of population reduction are suggested these programs can be achieved in a 10 years period:

- permanent movement of a part of government organizations to other parts of the country.
- providing facilities for families to emigrate and restriction in immigration.

Improvement of Tehran's environmental structure:

The environmental structure of Tehran is designed to facilitate, 5,000,000 people where as the present human population is said to be more that 10,000,000, the city has been developed in an horizontal and vertical manner and all developments have been taken place unsound, thereby many environmental problems have been created, as an example the following environmental issues are available in Tehran:

- Unsound development of housing complexes both horizontally and vertically.

- Development of bus terminals, air ports and railway inside the city.

- Lack of enough vegetation.

The above problems along with unfavorable atmospheric conditions and vehicular air pollution have caused extra environmental problems. Due to unsound concentrations of large-housing complexes, the wind speed has been affected and concentration of pollutants have been increased in some parts of downtown areas. Bus Terminals have been caused, the pollutants accumulation in surrounded areas.

Since 60 percent of the oxygen needed is produced by plants, vegetation for oxygen production in Teh ran is necessary. The per capita green area in Tehran is estimated to be 9 square meter in the year1997, (TERP,1997) where as the standard is at least 25 square meter. Since greening of Tehran has many advantages especially in reduction of air pollution. Hence, its development should be taken into account.

To improve the environmental structure of Tehran, the following programs is suggested.

- Shifting terminals from inside city to another areas.

- Planting and greening inside the city and providing a green-belt.

With plantation a remarkable percentage of pollutants are absorbed by plants and distribution of particulate matter is reduced and finally, with oxygen injection(through plantation) into the atmosphere, pollutants become diluted and their concentration gets highly reduced. 
Nomenclature:

$\mathrm{L}_{\mathrm{v}}$ : Vehicle Kilometers Traveled

$\mathrm{T}_{\mathrm{a}}$ : Atmospheric Temperature

Vs: Vehicle Speed

$\mathrm{R}_{\mathrm{H}}$ : Relative Humidity

$\mathrm{H}_{\mathrm{i}}$ : Inversion Height

$\mathrm{M}_{\mathrm{r}}$ : Mixing Ratio

$\mathrm{C}$ : Concentration of Pollutants

$\mathrm{C}_{\mathrm{H}}$ : Health Cost

$\mathrm{N}_{\mathrm{p}}$ : Population

$\mathrm{T}_{\mathrm{p}}$ : Tonnage of Pollutants

CLS: Cost of Life Saving

TD: Total Number of Deaths

DAP: Deaths Due to Air Pollution (\%)

W.P: Willingness to Pay

$\mathrm{Q}_{\mathrm{p}}$ : Quantity of Pollutants

$\mathrm{W}_{\mathrm{s}}$ :Wind Speed

APT: Air Pollution Due to Transportation (\%)

CHP: Cost of Hygiene Per Person

CWD: Cost of Water and Detergent

$\mathrm{N}_{\mathrm{v}}$ : Number of Vehicles to be Washed

CCW: Cost of Each Car Wash

$\mathrm{CH}$ : Cost of Hygiene

CHI: Cost of Human Illness

$\mathrm{Q}_{\mathrm{co}}$ : Quantity of CO

$\mathrm{Q}_{\underline{\mathrm{HC}}}$ : Quantity of $\mathrm{HC}$

\section{References}

AQCC (Air Quality Control Company) Tehran's Action Plan on Air Pollution Redution, 1997

Bowen, C., Donora, Pynnsylvania, Atlantic, 23-34, 1970

Brown, L. R., The world watch on global environmental issues, New York: W.W Norton, 1991

Cannon, J., The health costs of air pollution: A survey of studies 1984 to 1989, American Lung Association Excellent Review, New York, 1990

Cooper, C. D., F. C. Alley, Air pollution control: A design approval, Waveland press, Illinois,1986

Davani, Gh., Collection rules of islamic punishment and penalty, $1^{\text {st. }}$ Ed.,1996
DOE, Department Of Environment, Environmental Standards of Iran, Booklet, Published by Air Pollution Office of DOE, 1999

IDRO, Industrial development and renovation organization, Old and Poorly Maintained Vehicles, Booklet, 1998

Kazemnejad, A., Statistical Package for Social Sciences, 100 Statistical tests with SPSS, version 10: 2001

Pajohi, S., Supplier Automotive Parts Company, Economic evaluation of old vehicles, 1998

SAPCO (Supplier Automotive Parts Company), Old Vehicle Fleet, Booklet,1998

Schawing, R.C.,Longevity and benefits and costs of reducing various risks, Technol. Forecast. Soc., 13:333-345,1979

Soltanieh, M., Tehran emission reduction project, final report, 1997

Soltanieh, M., Tehran emission reduction project semiannual report,1997

Tehran Municipality, Beheshte Zahra Organization,1998 deaths during 1990-1998

Wadhwa, L. C., High way transportation and environmental management, James Cook University, Townsville, Qld, Astrulia, 1993 